\title{
sciforum
}

Conference Proceedings Paper

\section{Identification of moisture sources in the Atlantic Ocean for cyclogenesis processes}

\author{
Marni Pazos ${ }^{1, *}$ and Luis Gimeno ${ }^{2}$ \\ Published: 08/11/2017 \\ Academic Editor: Anita Drumond \\ 1 Universidad Nacional Autónoma de México; marni@unam.mx \\ 2 EPhysLab, Facultade de Ciencias, Universidade de Vigo, Ourense, 32004, Spain; 1.gimeno@uvigo.es \\ * Correspondence: marni@unam.mx; Tel.: +521-554-187-1165
}

\begin{abstract}
We used the Lagrangian model FLEXPART to identify the moisture sources of 110 tropical cyclones with cyclogenesis within an area comprised between $15-45 \mathrm{~W}$ and $8-20 \mathrm{~N}$. The model computes changes in the specific humidity from a 10-day period before the day of cyclogenesis of each tropical cyclone is and its contribution to the moisture budget of the region of interest. We calculated the values of the anomalies of the moisture budget to identify the main regions of moisture sources: the African coasts in the North Atlantic, the continental region over western Africa and along the South African coast. We also calculated the contribution of moisture sources from the South Atlantic to the cyclogenesis. The frequency distribution of these percentages shows two main peaks, one in $\sim 20 \%$ and other in $\sim 50 \%$. The path of tropical cyclones with $\sim 50 \%$ of moisture contribution from the South Atlantic made landfall more often than those with $\sim 20 \%$.
\end{abstract}

Keywords: tropical cyclones, moisture sources, lagrangian analysis

\section{Introduction}

The North Atlantic basin is delimited by the north hemisphere of America, Europe and Africa, and includes the Gulf of Mexico and the Caribbean Sea. It is characterized by providing the adequate environment for tropical cyclogenesis, particularly between $5^{\circ}$ and $15^{\circ}$ lat. The warm ocean waters of these basin provide the energy source for the tropical cyclone. Evaporation (latent heat flux) and heat transfer (sensible heat flux) from the ocean surface warm and moisten the tropical storm boundary layer. The heat and moisture fluxes and the potential energy comprise the moist static energy of the air. Conversion of this moist static energy into kinetic energy via convection is the mechanism by which a tropical cyclone intensifies [1].

Then, water vapor is an essential factor to the tropical cyclones development, and the identification of the sources of this moisture might be an improvement for forecasting.

Through the study of moisture transport from ocean sources that contribute to the cyclogenesis and development of tropical cyclones (TCs), we will approach the characterization of their climatology, particularly for those reaching extra-tropical latitudes, from both, zones where the cyclogenesis is carried out, and the areas that cover the TCs main path.

The identification of moisture sources can be performed through lagrangian analysis, where changes in the amount of moisture of an air parcel due to evaporation or precipitation, are assessed along an air parcel trajectory from one point of interest to another, identifying those places where moisture is gained or lost [2]. The main tool that we used to analyze moisture sources is the method 
The 1st International Electronic Conference on Hydrological Cycle (CHyCle-2017), 19 Noveber - 1 December 2017; Sciforum Electronic Conference Series, Vol. 1, 2017

developed by Stohl and James [3], the Flexible Particle dispersion model (FLEXPART) is a Lagrangian transport and dispersion model suitable for the simulation of a large range of atmospheric transport processes, and has proven to be highly efficient to diagnose changes in specific humidity along several trajectories related to sink regions [4 - 7].

Previous studies describe moisture sources and TCs [8][9], however, scarce studies on lagrangian analysis has been applied [10].

In this paper, we describe the TCs data base that we used and its characteristics, as well as the areas of interest of moisture sources, and further, we discuss the obtained results from the lagrangian model.

\section{Experiments}

The selection of the TCs for this study, was performed by consulting the data from the National Hurricane Center, HURDAT 2nd generation, available from http://www.aoml.noaa.gov/hrd/hurdat/ hurdat2-2051-2014-022315.html.

The ERA-Interim Reanalysis Data coupled to our FLEXPART software for the moisture sources calculations was available from 1979 to 2012, then the HURDAT records where examined at the same time span. We selected events with maximum sustained winds $>40$ knots and with cyclogenesis located inside the region comprised between $15^{\circ}-45^{\circ} \mathrm{W}$ and $8-20^{\circ} \mathrm{N}$, obtaining 110 events shown in Figure 1.

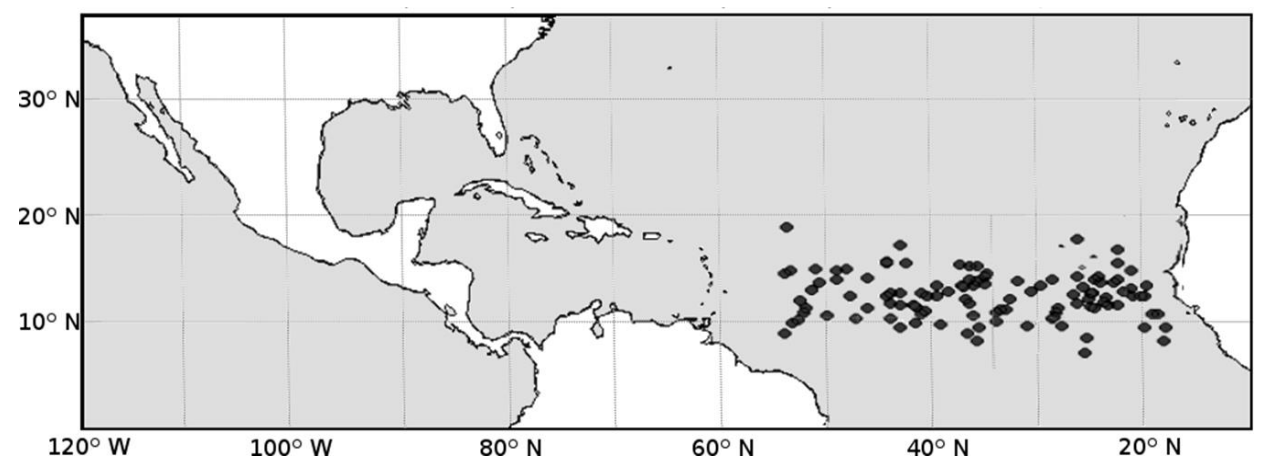

Figure 1. Location of the 110 events selected for the study

We performed the Lagrangian approach based on the FLEXPART model [3] to find the moisture sources associated with the cyclogenesis developed within the area of interest. The model divides the atmosphere homogeneously into a large number of virtual elements or "particles" with constant mass $\mathrm{m}$. These particles are then advected using 3D winds dataset and superimposed stochastic turbulent and convective motions. For each particle, the increases through evaporation (e) and decreases (through precipitation, $p$ ) in moisture can be calculated from changes in (q) with time $e-p=m(d q / d t)$. When adding $(e-p)$ for all the particles in the atmospheric column over an area, we can obtain sources and sinks of moisture $(\mathrm{E}-\mathrm{P})$, where $(\mathrm{E})$ is the evaporation and $(\mathrm{P})$ is the precipitation rate per unit area. The method calculates (E - P) from any specific region backwards or forwards in time. Here, we are interested on the evaporation areas defined as moisture sources.

The regions were calculated from six by six-degree boxes centered at the cyclogenesis point given by the records. The information needed to run the FLEXPART model were the geographic location of the four corners that define the boxes, as well as the corresponding day and month of each event. Then, we obtained the sum of all values of specific humidity from the moisture sources related to the particles inside each box 10 days before the day of cyclogenesis each year from 1979 to 2012 . 
The 1st International Electronic Conference on Hydrological Cycle (CHyCle-2017), 19 Noveber - 1 December 2017; Sciforum Electronic Conference Series, Vol. 1, 2017

Using these results, we calculated the anomalies of moisture sources related to the day and month when the TC occurred.

\section{Results}

Figure 2, shows the sum of anomalies calculated for the 110 events. The moisture sources for the TCs originated in the region of interest, are identified by the areas colored in yellow, orange and red, indicating the values of the anomalies.

In Figure 2a, the higher values are found in two main areas: in the north Atlantic front to the African coast, over west Africa, possibly due to the easterly African jet [10], and the area extended along the south Atlantic from the equator through the southern African coast. The gap between regions of moisture sources seems to be divided by the intertropical convergence zone.

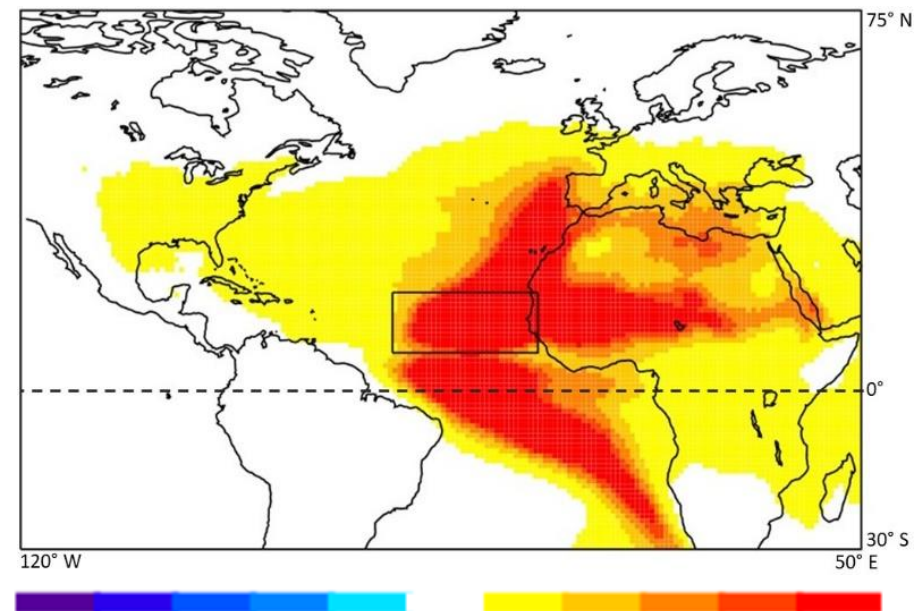

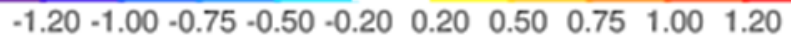

Figure 2. Accumulated anomalies of moisture sources from the $110 \mathrm{TCs}$ with cyclogenesis stage inside the area defined by the black line. The moisture sources from the South Atlantic comprise the area under the $0^{\circ}$ latitude (dotted line) between the South American and African coasts.

We calculated the percentage of the contribution of the moisture sources coming from the South Atlantic area and we also determine the frequencies distributions of these results (Figure 3).

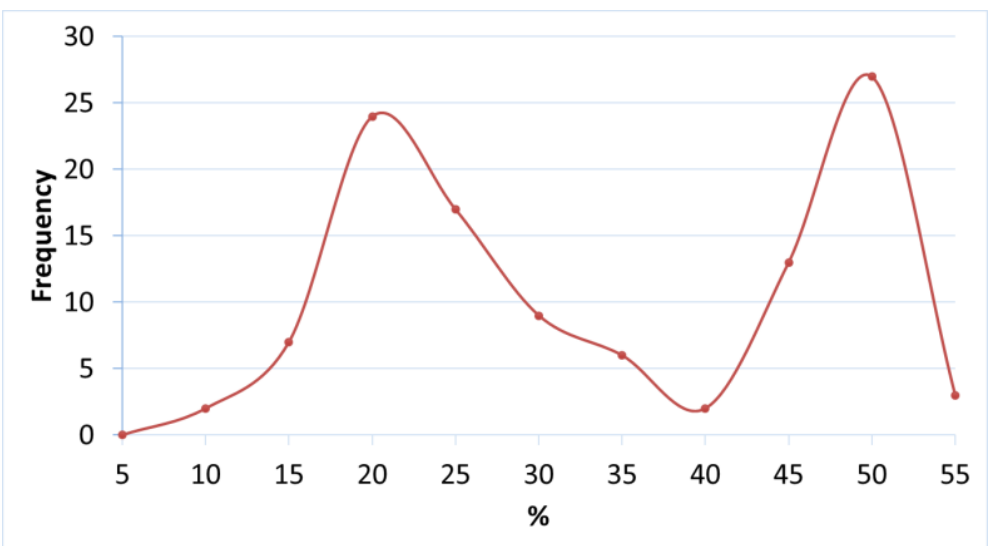

Figure 3. Frequency distribution of the percentage of contribution of the moisture sources from the South Atlantic. 
The 1st International Electronic Conference on Hydrological Cycle (CHyCle-2017), 19 Noveber - 1 December 2017; Sciforum Electronic Conference Series, Vol. 1, 2017

The graphic in Figure 3 shows two prominent peaks at around 20 and 50 percent, we delimited the number of events to two groups according to these main values and Figure 4 shows the tracks of each one of the events, Figure $4 \mathrm{a}$ with 20 percent and Figure $4 \mathrm{~b}$ with the 50 percent of contribution of moisture sources from the South Atlantic, which also shows higher occurrence of landfalling hurricanes compared to Figure 4a.

a)

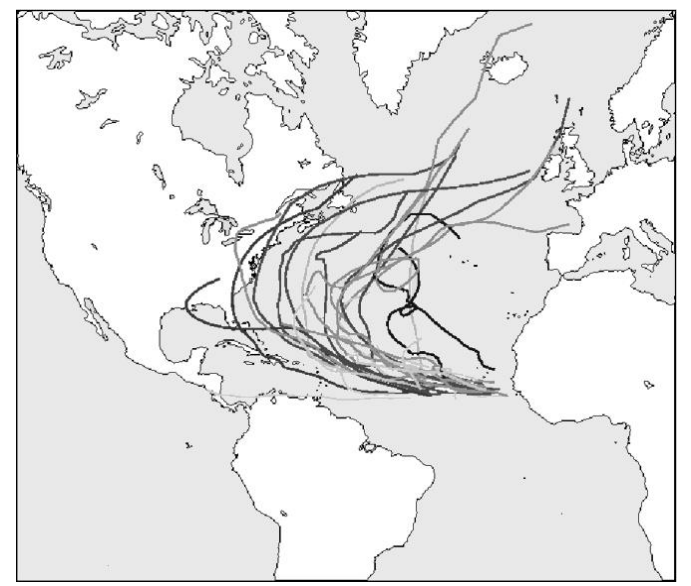

c)

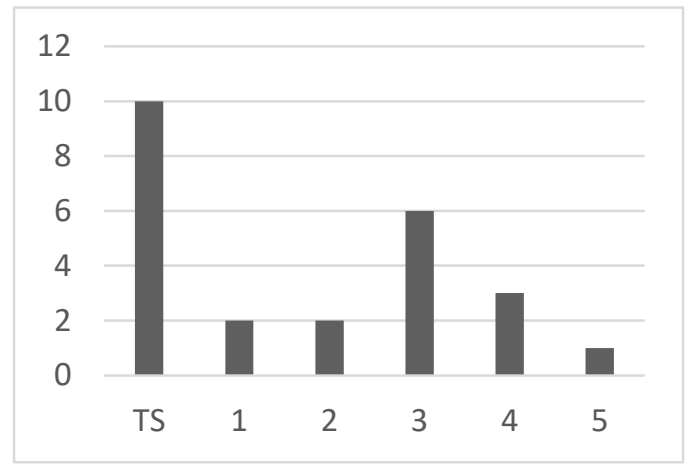

b)

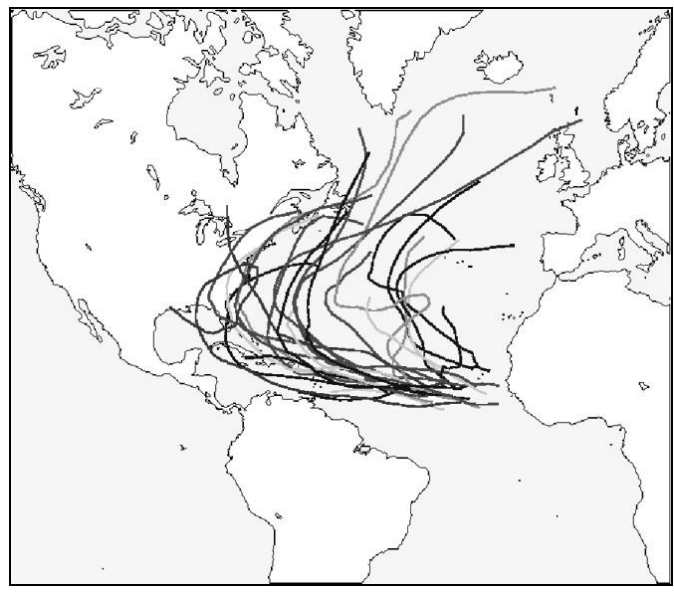

d)

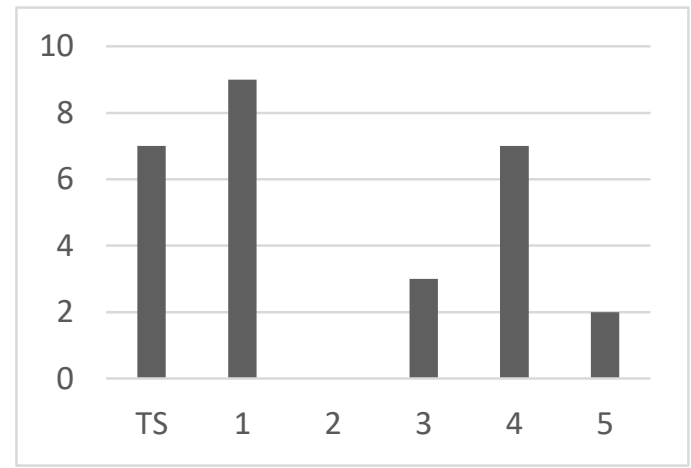

Figure 4. a) Track of tropical cyclones with $20 \%$ of moisture sources from the South Atlantic, b) Track of tropical cyclones with $50 \%$ of moisture sources from the South Atlantic, c) and d) number of events by category according to the contribution of $20 \%$ and $50 \%$ respectively.

Figures $4 \mathrm{c}$ and $4 \mathrm{~d}$ shows the number of events by hurricane category. According to it, we could characterize the group of $20 \%$ with 24 events and higher number of tropical storms and less major storms (hurricanes categories 4 and 5) compared with the group of $50 \%$ that comprises 28 events and higher number of category 1 and major hurricanes as well as landfalling events.

\section{Discussion and conclusions}

We were able to establish several areas of the possible origin of moisture sources modeling the patterns of the anomalies related to the specific TCs selected for this study.

The South Atlantic area has a complex dynamic that seems to play an important role in the North Atlantic tropical cyclogenesis. The use of FLEXPART on the identification process shows to be a novel tool. Few studies have been conducted on the moisture sources of tropical cyclones. According to 
The 1st International Electronic Conference on Hydrological Cycle (CHyCle-2017), 19 Noveber - 1 December 2017; Sciforum Electronic Conference Series, Vol. 1, 2017

Wang et al [9], the large Atlantic warm pool, associated with a decrease in sea level pressure and an increase in atmospheric convection and cloudiness, corresponds to a weak tropospheric vertical wind shear and a deep warm upper ocean, making a favorable environment for hurricane development, although it is not suggested the origin of the moisture sources of the convection and cloudiness, which as we can see from the results, at the stage of cyclogenesis, the South Atlantic near the African coast, represents an important area for moisture sources and in higher contribution to the cyclogenesis it seems to enhance the maximum wind velocities as well as to reach an eastward track, increasing the possibility of landfalling. The mechanisms of these possible interactions will be studied in future work.

\section{Acknowledgments: CONACyT grant 264009}

Author Contributions: L. Gimeno conceived and designed the experiments; M. Pazos performed the experiments; M. Pazos and L. Gimeno analyzed the data; M. Pazos and L. Gimeno wrote the paper.

Conflicts of Interest: The authors declare no conflict of interest.

\section{Abbreviations}

The following abbreviations are used in this manuscript:

TCs: tropical cyclones

\section{References}

1. Laing, A. and Evans J., Introduction to Tropical Meteorology, University Corporation for Atmospheric Research, 2011.

2. Sodeman, H..; Schwierz, C., Wernli, H. Interannual variability of Greenland winter precipitation sources: Lagrangian moisture diagnostic and North Atlantic Oscillation influence. J. Geophys. Res. 2008, 113, D031107, doi: 10.1029/2007JD008503.

3. Stohl, A., and P. James, A Lagrangian analysis of the atmospheric branch of the global water cycle. Part II: Moisture transports between the Earth's ocean basins and river catchments, J. Hydrometeorol. 2005, 6, 961984.

4. Gimeno, L., R. Nieto, R. M. Trigo, S. Vicente-Serrano, and J. I. López- Moreno, Where does the Iberian Peninsula moisture come from? An answer based on Lagrangian approach, J. Hydrometeorol., 2010b, 11, 421- 436, doi:10.1175/2009JHM1182.1.

5. Gimeno, L., R. Nieto, A. Drumond, A. M. Durán-Quesada, A. Stohl, H. Sodemann, and R. M. Trigo, A close look at oceanic sources of continental precipitation, Eos Trans. AGU, 2011, 92(23). doi: 10.1029/ 2011EO230001.

6. Gimeno L, Nieto R, Drumond A, Castillo R, and R.M Trigo, Influence of the intensification of the major oceanic moisture sources on continental precipitation. Geophys. Res. Lett., 2013, doi: 10.1002/grl.50338.

7. Nieto, R., Castillo, R. Drumond, a., and Gimeno 1., A catalog of moisture sources for continental climatic regions, Water Resour. Res, 2014 DOI: 10.1002/2013WR013901

8. Wang, C., Lee S.-K., Enfield, D. B., Impact of the Atlantic Warm Pool on the Summer Climate of the Western Hemisphere, J. Clim., 2007, 21, 5021-5040. doi: 10.1175/JCLI4304.1.

9. Wang, C., Lee, S. K. and Enfield, D. B., Climate response to anomalously large and small Atlantic warm pools during the summer, J. Clim., 2008, 21, 2437-2450, doi:10.1175/2007JCLI2029.1.

10. Drumond, A., Nieto, R., and Gimeno, L. On the contribution of the Tropical Western Hemisphere Warm Pool source of moisture to the Northern Hemisphere precipitation through a Lagrangian approach, J. Geophys. Res., 2011, 116, D00Q04, doi:10.1029/2010JD015397

11. HURDAT Re-analysis. Available online: http://www.aoml.noaa.gov/hrd/hurdat/hurdat2-1851-2015021716.txt (last accessed: 2 November 2017). 